\title{
ASPECTOS DA RESISTÊNCIA DE BOVINOS AO CARRAPATO RHIPICEPHALUS (BOOPHILUS) MICROPLUS
}

\author{
BOVINE RESISTANCE TO RHIPICEPHALUS (BOOPHILUS) MICROPLUS TICKS
}

\author{
Biegelmeyer, P. ${ }^{*}$, Nizoli, L.Q. ${ }^{2}$, Cardoso, F.F. ${ }^{3}$ e Dionello, N.J.L. ${ }^{1}$
}

${ }^{1}$ Departamento de Zootecnia. Faculdade de Agronomia Eliseu Maciel. Universidade Federal de Pelotas. Pelotas, RS. Brasil. *patriciabiegel@gmail.com.br

${ }^{2}$ Departamento de Veterinária Preventiva. Faculdade de Veterinária. Universidade Federal de Pelotas. Pelotas, RS. Brasil.

${ }^{3}$ Embrapa Pecuária Sul. Bagé, RS. Brasil.

\section{AdDitional KEYWORDS}

Adaptability. Cattle production. Genetic improvement. Molecular markers.

\section{RESUMO}

O parasitismo pelo carrapato Rhipicephalus (Boophilus) microplus em países tropicais e subtropicais é associado a grandes quedas nos índices de produtividade dos rebanhos. O controle convencional do parasita, baseado na utilização de drogas carrapaticidas, há anos vem demonstrando sua ineficácia como estratégia de controle a longo prazo, através dos recorrentes relatos de populações de ectoparasitas resistentes às formulações comercialmente disponíveis. A ocorrência de variabilidade genética para resistência ao carrapato em bovinos indica a possibilidade de ganhos genéticos pela seleção de animais resistentes e o uso desta ferramenta como estratégia auxiliar no controle efetivo do parasita. O objetivo do presente estudo é apresentar resultados de estudos avaliando a resistência de bovinos ao carrapato, identificar fatores não genéticos que afetam os fenótipos de resistência, e descrever algumas descobertas na área da genética molecular que poderão auxiliar no processo de identificação de animais resistentes.

\section{SUMMARY}

Parasitism by cattle ticks Rhipicephalus (Boophilus) microplus in tropical and subtropical countries is responsible for decreased livestock production. Conventional control of parasites is based on the use of chemical products, but

\section{Palavras chave adicionais}

Adaptabilidade. Bovinocultura. Marcadores moleculares. Melhoramento genético.

increased instances of resistance in ticks to commercially available products show the inefficiency of this method on the long run. Existence of genetic variability for tick resistance in cattle indicates the possibility of genetic gains through selection of resistant animals and the use of this approach as an effective strategy for tick control. The objectives of this study are to summarize results of previous studies of bovine resistance to the cattle tick, identify non genetic effects on this characteristic, and describe discoveries in molecular genetics that will help to identify resistant animals.

\section{INTRODUÇÃO}

O carrapato bovino Rhipicephalus (Boophilus) microplus é apontado como um dos principais responsáveis por perdas econômicas nos sistemas de produção dos países tropicais e subtropicais. Os prejuízos causados pelo parasita são decorrentes tanto de sua ação direta sobre o hospedeiro, como anemias provocadas pelo hematofagismo e desvalorização do couro pela ocorrência de lesões e mí́ases, bem como de perdas indiretas relacionadas à transmissão dos patógenos responsáveis pela babesiose e anaplasmose, hemoparasitoses que caracterizam o complexo da Tristeza 
Parasitária Bovina. Diminuição na produção de leite e carne e altos custos com tratamentos químicos, equipamentos, instalações e mão de obra contribuem para compor o quadro de agravantes deste parasitismo. Diferentes formas de controle têm sido propostas, e pesquisas direcionadas à busca de alternativas de controle são diversas.

O controle biológico dos carrapatos engloba princípios apoiados no conhecimento da epidemiologia e ecologia destes ácaros, aliado a técnicas de manejo dos animais e das pastagens, dificultando a sobrevivência das fases de vida livre do parasita. Entre as práticas preconizadas estão a rotação de pastagens, cultivo de espécies forrageiras com ação repelente ou carrapaticida sobre as larvas, alternância de pastoreio entre ovinos e bovinos, ação de predadores naturais e uso de microorganismos patogênicos aos carrapatos, como fungos e bactérias (Alves-Branco et al., 2000; Sonenshine et al., 2006; Leemon et al., 2008; Samish et al., 2008; Santi et al., 2009).

Os avanços acumulados nas últimas décadas na área da biologia molecular permitiram incluir também o controle imunológico como ferramenta auxiliar no controle do $R$. (B.) microplus, destacandose os trabalhos realizados com o desenvolvimento de vacinas contendo o antígeno recombinante Bm86 (Rodríguez Valle et al., 2004; Willadsen, 2006, 2008; de la Fuente et al., 2007). Estas vacinas diminuem o número e peso das fêmeas ingurgitadas, prejudicando a capacidade reprodutiva do parasita (Almazán et al., 2010).

Historicamente, o método mais explorado de controle do carrapato bovino tem sido o químico, baseado na utilização de princípios ativos que atuam na fase de vida parasitária dos vetores. O uso indiscriminado de acaricidas tem, entretanto, culminado no aparecimento de populações de $R$. (B.) microplus resistentes aos produtos, ge- rando grandes despesas com tratamentos ineficazes e necessidade de altos investimentos para descoberta de novas drogas. O uso intensivo de carrapaticidas também apresenta como limitante de sua utilização a possibilidade de ocorrência de resíduos na carne, leite e meio ambiente, o que vai de encontro às novas exigências dos mercados consumidores, com demanda crescente por alimentos mais saudáveis obtidos através de uma produção sustentável e ecologicamente correta.

As limitações apresentadas pelos métodos de controle atualmente disponíveis indicam a necessidade de oferecer aos criadores novas alternativas, mas que ao mesmo tempo não imponham maiores gastos no processo de obtenção do produto final. A resistência genética dos bovinos ao carrapato atende a tais requisitos, podendo ser considerada o fator de maior influência sobre o custo do controle dos parasitas, por ser de baixo custo e oferecer benefícios permanentes.

Este trabalho objetiva abordar alguns aspectos da resistência genética de bovinos ao carrapato, apresentando evidências sobre a variabilidade genética observada nos animais, fatores ambientais que podem afetar esta característica, bem como considerações sobre o uso de marcadores genéticos relacionados à resistência ao carrapato em bovinos.

\section{VARIABILIDADE GENÉTICADA RESISTÊNCIA A RHIPICEPHALUS(B.) MICROPLUS}

Fatores que afetam o nível de resistência de bovinos ao $R$. (B.) microplus são constantemente discutidos na literatura, sendo o fator raça o que apresenta maior consenso entre os autores. A maior tolerância de animais Bos indicus quando comparados a Bos taurus é amplamente reportada, e estudos envolvendo cruzamentos entre animais destes grupos apontam, inclusive, uma proporcionalidade entre o número de 


\section{RESISTÊNCIA DE BOVINOS AO CARRAPATO RHIPICEPHALUS MICROPLUS}

genes zebuínos e o grau de resistência dos hospedeiros (Cardoso, 2000; Santos Jr. et al., 2000; Silva et al., 2006a; Ayres et al., 2009).

As raças zebuínas apresentam maiores níveis de resistência quando comparadas a raças crioulas latino-americanas que, por sua vez, são mais tolerantes que as europeias, apesar de terem se originado destas (Utech et al., 1978a). Mesmo após repetidas infestações, hospedeiros suscetíveis sempre apresentam um maior número de parasitas quando comparados aos resistentes (Mattioli et al., 2000).

Em infestações artificiais, onde se tem controle sobre o número de larvas que infestarão o animal, a resistência de bovinos aos carrapatos pode ser medida pelo percentual de larvas que não conseguem se desenvolver até a fase adulta. Nestas condições, animais $B$. indicus apresentam em torno de $99 \%$ de resistência, cruzados $B$. indicus $\mathrm{x}$ B. taurus têm resistência de 95-97\%, e B. taurus de $85-90 \%$ (Utech et al., 1978a).

O mecanismo responsável por essa resistência é um fenômeno complexo e ainda pouco compreendido. Muitos estudos têm associado os fenótipos resistentes a mecanismos imunológicos adquiridos, após a exposição dos animais a infestações (Kashino et al., 2005). Tal fato foi observado por Wagland (1975) em rebanhos australianos das raças Brahman (B. indicus) e Shorthorn (B. taurus), sem contato prévio com $R$. (B.) microplus e submetidos a infestações artificiais. Neste estudo, após a primeira exposição os dois grupos apresentaram resultados similares quanto ao número de fêmeas adultas do parasita presente no corpo dos animais. Entretanto, após quatro infestações sucessivas, bovinos Shorthorn apresentaram-se significativamente mais infestados que os bovinos Brahman.

No Brasil, Veríssimo et al. (2002) compararam fêmeas das raças Holandês, Gir e mestiças, e atribuíram a menor resistência às vacas Holandês e a maior às vacas Gir. Analisando diferentes grupos genéticos, Silva et al. (2007) expuseram fêmeas bovinas a quatro infestações artificiais, atribuindo a menor suscetibilidade a novilhas Nelore, resistência intermediária a fêmeas Canchim x Nelore, e maior carga parasitária nos produtos do cruzamento entre Angus x Nelore e Simental x Nelore. Ayres et al. (2009) analisaram dados de contagens de carrapatos em bovinos Braford pertencentes a um programa de melhoramento e verificaram que o número de carrapatos diminuía à medida que a proporção de genes $B$. indicus aumentava.

Em um estudo comparativo entre as resistências demonstradas por diferentes raças de bovinos de corte na Austrália, Frisch e O'Neill (1989) apresentaram a seguinte classificação decrescente: Brahman e Boran (B. indicus indiano e africano, respectivamente), Belmont $\mathrm{BX}$ (Brahman x Hereford x Shorthorn), Belmont Red (Africander x Hereford x Shorthorn), Belmont Adaptur (Hereford x Shorthorn), Tuli (B. taurus sul-africano), e Charolês ( $B$. taurus europeu), sendo a última apontada pelos autores como a raça mais suscetível.

Diferentes níveis de suscetibilidade são observados não apenas entre $B$. indicus e $B$. taurus, mas também entre raças de mesma origem e entre indivíduos de mesmo grupo racial. Entre as raças europeias, por exemplo, bovinos Jersey são apontados como mais resistentes quando comparados a outros grupamentos de B. taurus, enquanto na raça Brahman, considerada uma das mais resistentes entre as zebuínas, cerca de $10 \%$ dos animais apresentam apenas resistência intermediária ao carrapato (Utech et al., 1978a).

A ocorrência de variabilidade genética demonstra que há potencial para o melhoramento desta característica através da seleção de bovinos resistentes, já que as estimativas de herdabilidade relatadas por diversos autores indicam que a seleção para resistência ao parasita pode ser altamente 
eficiente. Andrade et al. (1998) estimaram uma herdabilidade média de 0,26 para a contagem de carrapatos em rebanhos Gir, valor próximo dos encontrados por Fraga et al. (2003) em fêmeas da raça Caracu $\left(\mathrm{h}^{2}=\right.$ 0,22), e por Machado et al. (2010) em uma população $\mathrm{F}_{2}$ resultante do cruzamento entre animais Gir e Holandês $\left(\mathrm{h}^{2}=0,21\right)$. A partir de dados de contagens de carrapatos em rebanhos australianos de B. taurus, Henshall (2004) encontrou uma herdabilidade média de 0,41. Em bovinos Braford, Cardoso et al . (2006) observaram herdabilidade de 0,34, valor acima dos encontrados por Regitano et al. (2006), Silva et al. (2006b) e Ayres et al. (2009), que estimaram, respectivamente, herdabilidades de 0,15, 0,12 e 0,09 em bovinos cruzados. Biegelmeyer et al. (2011), analisando a herdabilidade da característica de contagem de carrapatos realizada na região do entrepernas e em um dos lados do corpo de bovinos Hereford e Braford registraram, respectivamente, valores de 0,16 e 0,24 .

$\mathrm{Na}$ Austrália, onde as condições climáticas são semelhantes às do Brasil, a seleção genética de bovinos para resistência como estratégia de controle do carrapato já é utilizada, e experimentos realizados já demonstraram a eficiência desta característica como critério de seleção. Após um período de 15 anos de seleção para resistência em um rebanho Australian Illawara Shorthorn, Utech e Wharton (1982) relataram que o número de animais com fenótipos de alta resistência aumentou de $89,2 \%$ para $99 \%$, sem reflexos negativos sobre a produção leiteira, o que sugere a possibilidade de melhoramento simultâneo de ambas as características.

\section{FATORES AMBIENTAIS QUE AFETAM A RESPOSTA IMUNE A OS CARRAPATOS}

A expressão das características fenotípicas de um animal resulta da ação de seu conjunto de genes, dos efeitos ambientais e das interações genótipo x ambiente. Considerando que parte do ciclo de vida do carrapato ocorre no ambiente, as variações quanto aos níveis de infestações apresentados por bovinos podem ser atribuídas tanto a fatores genéticos como a efeitos ambientais, que em combinação determinam uma maior ou menor carga parasitária nos indivíduos. Tais influências devem ser levadas em consideração em estratégias de melhoramento dos rebanhos, como forma de aumentar a acurácia dos valores genéticos preditos dos animais e, consequentemente, a eficiência do processo de seleção para a característica de resistência.

Avaliando os fatores ambientais que poderiam contribuir para diferentes graus de parasitismo apresentados por bovinos, Silva et al. (2006a) verificaram que o sexo exerceu efeito significativo sobre o número de parasitas contados em animais de diferentes composições raciais, sendo os machos mais afetados que as fêmeas. Utilizando bovinos cruzados Gir x Holandês, Martinez et al. (2006) também observaram maior suscetibilidade nos machos, o que pode ser resultado da interferência dos hormônios sexuais sobre a resposta imune desenvolvida por cada categoria.

Os hormônios sexuais também parecem estar envolvidos no grau de resistência ao carrapato de fêmeas em diferentes estados fisiológicos. Utech et al. (1978b) e Fraga et al. (2003) observaram em um rebanho da raça Caracu que vacas não gestantes foram mais resistentes que vacas gestantes. Silva et al. (2010) também verificaram efeito do estádio fisiológico sobre a contagem de carrapatos em bovinos de quatros grupos genéticos, relatando maior infestação em novilhas prenhes que em novilhas vazias, e maior número de carrapatos em vacas pluríparas com bezerro que em pluríparas sem bezerro e primíparas. No final da gestação e ao longo da lactação, as fêmeas tendem a demonstrar maior vulnerabili- 


\section{RESISTÊNCIA DE BOVINOS AO CARRAPATO RHIPICEPHALUS MICROPLUS}

dade às infestações, fato que está relacionado ao estresse da gestação e às oscilações hormonais nestes períodos. Um dos hormônios responsáveis por esta queda na imunidade é a prolactina, envolvido na produção de leite e que possui certo efeito depressor sobre o sistema imunológico. De acordo com Soulsby (1987), o aumento da prolactina no período periparto pode causar uma imunossupressão de origem endócrina, cujo mecanismo ainda não está completamente identificado.

Estudando o efeito da idade sobre as infestações, Utech et al.(1978b) compararam fêmeas das raças Australian Illawara Shorthorn e Brahman submetidas a infestações artificiais, verificando que vacas com idade entre três e quatro anos se mostraram mais resistentes que vacas com cinco a seis anos de idade. Gomes (1992) e Andrade et al. (1998) verificaram um acréscimo linear no número de carrapatos com o aumento da idade dos animais, enquanto Fraga et al. (2003) relataram efeito quadrático desta variável, demonstrando que os animais mais velhos e os mais jovens foram mais resistentes quando expostos naturalmente ao parasita. Bezerras de diferentes grupos genéticos infestadas naturalmente no estudo de Silva et al. (2010) também apresentaram menor carga parasitária que as novilhas, o que possivelmente está associado à imunidade passiva adquirida pelos anticorpos colostrais. Este é um importante fator ambiental a ser considerado na prospecção dos níveis populacionais de $R$. (B.) microplus em animais de diferentes faixas etárias, pois pode, por exemplo, induzir a estimativas subestimadas dessas populações em bovinos jovens.

O efeito da época do ano sobre o grau de infestação pelo carrapato é descrito por diversos trabalhos, que apresentam resultados variados. Gomes (1992), em uma população de bovinos da raça Gir, descreveu a ocorrência dos picos das infestações durante o inverno, enquanto
Andrade et al. (1998) registraram as maiores infestações durante o outono e as menores no verão, em animais da mesma raça. Por outro lado, Fraga et al. (2003) observaram que em animais da raça Caracu a maior incidência de carrapatos ocorreu nos meses de verão. Silva et al. (2010) também compararam o efeito da estação do ano sobre o número de carrapatos em bovinos de corte, demonstrando que os animais foram mais suscetíveis no outono e no inverno.

Em grande parte do território brasileiro, o parasitismo por $R$. (B.) microplus se manifesta nos rebanhos ao longo do ano inteiro, em decorrência das condições climáticas propícias ao seu desenvolvimento. Observam-se, no entanto, oscilações nas populações do parasita de acordo com o microclima específico de cada região. Desta forma, resultados divergentes quanto à estação de maior ocorrência destes ácaros são absolutamente compreensíveis, visto que a fase de vida livre destes vetores é altamente influenciada pelo ambiente, principalmente pela temperatura e umidade. Maiores populações de $R$. (B.) microplus no verão poderiam ser explicadas pelo maior estresse térmico ao qual os animais são submetidos, enquanto o aumento de carrapatos no outono pode ser atribuído à resposta fisiológica do hospedeiro ao encurtamento do fotoperíodo, que prejudica a capacidade imunológica dos bovinos (Oliveira et al., 1989). A disponibilidade diferenciada de forrageiras de qualidade ao longo do ano também pode afetar, indiretamente, o nível de resistência dos animais, visto que as deficiências nutricionais estão relacionadas a quedas na imunidade dos animais.

\section{MARCADORES MOLECULARESE RESISTÊNCIA}

Os novos focos de pesquisa possibilitados pelos avanços na biologia molecular nos últimos anos consolidaram a 
importância do melhoramento genético como forma de aumentar a produtividade dos rebanhos. Os procedimentos clássicos de avaliação, que consideram os fenótipos individuais e de indivíduos aparentados, hoje já podem ser assistidos por informações obtidas diretamente do material genético dos animais, através dos marcadores moleculares. Considerando que a identificação de genótipos de resistência a ectoparasitas através de métodos quantitativos convencionais depende da exposição prévia dos animais a infestações, o que pode acarretar prejuízos aos candidatos à seleção, a seleção genômica para resistência se mostra como uma poderosa ferramenta auxiliar aos atuais programas de melhoramento, pois possibilitaria antecipar a escolha dos genótipos superiores, sem a necessidade de exposição dos animais aos carrapatos.

A maioria das características de interesse econômico na pecuária é controlada por muitos genes de pequeno efeito individual, que estão sujeitos a influências ambientais. No entanto, alguns estudos já sugeriram a ocorrência de genes de efeitos maior para resistência ao carrapato, que poderiam ser explorados no processo de seleção de animais resistentes. Um destes genes foi identificado em bovinos da raça sintética Adaptur, produtos do cruzamento entre Hereford e Shorthorn. De acordo com Frisch (1994), vários anos de seleção demonstraram que o número médio de parasitas em animais com 0,1 ou 2 cópias do gene foi de 128, 36 e 7, respectivamente, demonstrando a potencialidade da utilização de genes de grande efeito.

Os segmentos cromossômicos que controlam as características quantitativas, como a resistência a ectoparasitas, são denominados Quantitative Trait Loci (QTLs). As pesquisas no campo da genômica aplicada à produção animal têm constantemente divulgado resultados de QTLs e polimorfismos em genes relacionados a características de interesse econômico. Os marcadores disponíveis comercialmente para a espécie bovina estão associados principalmente a características de desenvolvimento ponderal, como pesos e ganhos de peso em diferentes idades. A despeito da importância assumida pelos transtornos causados pelo parasitismo por $R$. (B.) microplus, ainda existem poucos resultados sobre marcadores para resistência a este ectoparasita, o que pode ser explicado pela dificuldade de identificação em larga escala de indivíduos resistentes, e pelo fato de se tratar de um problema expressivo apenas em países de climas tropicais e subtropicais.

A identificação de QTLs no DNA pode ser baseada nos chamados genes candidatos, através da detecção de polimorfismos em genes diretamente relacionados à característica de interesse, ou no mapeamento genético. $\mathrm{O}$ mapeamento genético busca determinar polimorfismos relacionados a regiões genéticas de interesse, mesmo que o gene responsável pelo fenótipo desejável seja desconhecido (Womack, 1993). Um dos tipos de marcadores moleculares mais polimórficos utilizados atualmente são os microssatélites, formados por uma sequência de até seis nucleotídeos repetidos em tandem. Os avanços tecnológicos e o recente sequenciamento do genoma bovino disponibilizaram nos últimos anos outra classe de marcadores, denominados SNPs (Single Nucleotide Polimorphisms), que constituem polimorfismos em um único par de bases, muito úteis na construção de mapas genéticos de alta resolução devido a sua alta frequência e distribuição homogênea ao longo de todo o genoma (Bovine Genome Sequencing and Analysis Consortium, 2009; Li et al., 2009).

Entre os genes mais estudados do sistema imunológico e associados à resistência dos hospedeiros estão os genes do complexo maior de histocompatibilidade (bovine lymphocyte antigen - BoLA). Localizados no cromossomo 23 , estes genes codificam glicoproteínas de superfície celular que 


\section{RESISTÊNCIA DE BOVINOS AO CARRAPATO RHIPICEPHALUS MICROPLUS}

atuam como receptores nas células apresentadoras de antígenos, acoplando e apresentando peptídeos antigênicos para os linfócitos $\mathrm{T}$, responsáveis pelo início da resposta imune (Tizard, 2008). Desta forma, variações nos genes de classe I e II deste complexo poderiam influenciar a capacidade imune dos animais (Takeshima e Aida, 2006), e os mecanismos de resistência e desenvolvimento da resposta imunológica poderiam ser elucidados a partir da compreensão da expressão destes genes. Avaliando rebanhos leiteiros mistos, Martinez et al. (2004) encontraram relação significativa entre a contagem de carrapatos e os alelos 10 e 42 do gene BoLA-DRB3.2. Associações entre a resistência e marcadores microssatélites na região de classe II do gene BoLA também foram relatadas por Acosta-Rodríguez et al. (2005), Martinez et al. (2005, 2006) e Untalan et al. (2007).

Estudos desenvolvidos por Gasparin et al. (2007), Regitano et al. (2008) e Machado et al. (2010) buscaram identificar QTLs para resistência ao carrapato em animais Gir $\mathrm{x}$ Holandês através da varredura do genoma com marcadores microssatélites, detectando QTLs nos cromossomos 2, 5, 7, 10, 11, 14, 23 e 27. Recentemente, Porto Neto et al. (2010a, 2011) confirmaram a ocorrência de QTLs nos cromossomos 3 e 10. Em um estudo de associação do genoma utilizando SNPs realizado por Barendse (2007), um grande número de polimorfismos de base única associados à característica de resistência ao $R$. (B.) microplus foi observado em diversas regiões genômicas. Também em um estudo de associação com SNPs, Turner et al. (2010) demonstraram a ocorrência de uma baixa correlação entre os efeitos dos alelos envolvidos com a produção de leite e a contagem de carrapatos, indicando que uma seleção pela característica de resistência provavelmente não prejudicaria a produção leiteira do rebanho. Porto Neto et al. (2010b) utilizaram a metanálise para combinar os resultados dos estudos de associação de Turner et al. (2010) e os dados das análises de expressão de genes para resistência na pele de bovinos das raças Brahman e Holandesa realizadas por Piper et al. (2008), e indentificaram que ambos os trabalhos apresentaram regiões genômicas em comum nos cromossomos Bos taurus (BTA) de número 2, 10, 13 e 19, incluindo 20 genes.

Os genes que contribuem para os fenótipos de resistência ainda não estão completamente descritos, e muitos trabalhos já foram conduzidos no sentido de elucidar questões relativas tanto à imunidade inata do hospedeiro (Moraes et al., 1992; Andrade et al., 1998; Turni et al., 2002; Veríssimo et al., 2002; Fraga et al., 2003) como à imunidade adquirida após exposições ao carrapato (Bechara et al., 2000; Szabó et al., 2003; Kashino et al., 2005; Skallová et al., 2008; Piper et al., 2008, 2009, 2010; Carvalho et al., 2008, 2011). Considerando os resultados obtidos pelas pesquisas com marcadores moleculares, Lôbo et al. (2010) destacam que a próxima fase no processo de compreensão dos mecanismos genéticos envolvidos na expressão da resistência será a identificação dos genes responsáveis pelos efeitos apresentados pelos QTLs mapeados.

\section{CONSIDERAÇÕES FINAIS}

Os diferentes níveis de suscetibilidade de bovinos ao carrapato $R$. (B.) microplus indicam diferenças nos mecanismos imunológicos desenvolvidos pelos hospedeiros em resposta ao parasita. A compreensão destes mecanismos e a identificação de genes envolvidos na resistência são pontos chave tanto para os programas de melhoramento bovino atuais, cada vez mais assistidos por metodologias de análise molecular, como para a descoberta de novos antígenos com capacidade imunoprotetora, capazes de otimizar as vacinas já disponíveis.

A tecnologia dos marcadores genéticos aumenta as expectativas depositadas sobre 
a seleção de bovinos resistentes como estratégia de controle do carrapato, pois possibilitará a identificação mais precoce e pontual dos animais geneticamente superiores. A classificação dos indivíduos com base na avaliação direta de seu genótipo aumentará a acurácia das estimativas dos

\section{BIBLIOGRAFIA}

Acosta-Rodríguez, R., Alonso-Morales, R., Balladares, S., Flores-Aguilar, H., GarciaVazquez, Z. and Gorodezky, C. 2005. Analysis of BoLA class II microsatellites in cattle infested with Boophilus microplus ticks: class II is probably associated with susceptibility. Vet Parasit, 127: 313-321.

Almazán, C., Lagunes, R., Villar, M., Canales, M., Rosario-Cruz, R., Jongejan, F. and Fuente, J. de la. 2010. Identification and characterization of Rhipicephalus (Boophilus) microplus candidate protective antigens for the control of cattle tick infestations. Parasitol Res, 106: 471-479.

Alves-Branco, F.P.J., Pinheiro, A.C. and Sapper, M.F.M. 2000. Controle dos principais ectoparasitos e endoparasitos em bovinos de corte no Rio Grande do Sul. Embrapa Pecuária Sul. Bagé, RS. Série Documentos. n.18. 54 pp.

Andrade, A.B.F., Silva, R.G. Costa,, A.J., Rocha, U.F. and Landim, V.J.C. 1998. Genetic and environmental aspects of the resistance of zebu cattle to the tick Boophilus microplus. In: World Congress on Genetics Applied to Livestock Production, 6. Proceedings... Armidale, Australia. pp. 339-342.

Ayres, D.R., Baldi, F., Diaz, I.D.P.S., Albuquerque, L.G. and Roso, V.M. 2009. Estimativas de parâmetros genéticos para números de carrapatos (Boophilus microplus) em bovinos da raça Braford, utilizando o método da máxima verossimilhança restrita e inferência Bayesiana. In: Reunião Anual da Sociedade Brasileira de Zootecnia, 46. Anais... Maringá, PR.

Barendse, W. 2007. Assessing tick resistance in a bovine animal for selecting cattle for tick resistance by providing a nucleic acid from the bovine animal and assaying for the occurrence of a single nucleotide polymorphism (SNP). Patent application WO2007051248-A1. pp. 1-146.

Bechara, G.H., Morelli Jr., J. and Szabó, M.P.J. valores genéticos, contornando os efeitos exercidos pelo ambiente sobre os fenótipos de resistência. Tais efeitos devem ser considerados nos métodos quantitativos clássicos de avaliação genética, como forma de possibilitar uma maior confiabilidade nos parâmetros estimados.

2000. Skin test and tick immune status in susceptible and resistant cattle in Brazil. Ann NY Acad Sci, 916: 570-575.

Biegelmeyer, P., Cardoso, F.F., Gulias-Gomes, C.C., Roso, V.M. and Dionello, N.J.L. 2011. Estimation of (co)variance components and genetic parameters for tick resistance in beef cattle measured by two different body regions. Reunión de la Asociación Latinoamericana de Producción Animal, 22. Proceedings... Montevideo. Uruguay. pp. 228.

Bovine Genome Sequencing and Analysis Consortium. 2009. The genome sequence of taurine cattle: A window to ruminant biology and evolution. Science, 324: 528-532.

Cardoso, V. 2000. Avaliação de diferentes métodos de determinação da resistência genética ao carrapato Boophilus microplus em bovinos de corte. Dissertação (Mestrado em Zootecnia). Faculdade de Ciências Agrárias e Veterinárias, UNESP. Jaboticabal. $108 \mathrm{pp}$.

Cardoso, V., Fries, L.A., Roso, V.M. and Brito, F.V. 2006. Estimates of heritability for resistance to Boophilus microplus tick evaluated by an alternative method in a commercial Polled Hereford $x$ Nelore population in Brazil. World Congress on Genetics Applied to Livestock Production, 8. Proceedings... Belo Horizonte, MG. Carvalho, W.A., Bechara, G.H., Moré, D.D., Ferreira, B.R., Silva, J.S. da and Miranda Santos, I.K.F. de. 2008. Rhipicephalus (Boophilus) microplus: Distinct acute phase proteins vary during infestations according to the genetic composition of the bovine hosts, Bos taurus and Bos indicus. Exp Parasitol, 118: 587-591.

Carvalho, W.A., Lanella, P., Arnoldi, F.G.C., Caetano, A.R., Maruyama, S.R., Ferreira, B.R., Conti, L.H.A., Silva, M.R.M. da, Paula, J.O.F., Maia, A.A.M. and Miranda Santos, I.K.F. de. 2011. Haplotypes of the bovine IgG2 heavy 


\section{RESISTÊNCIA DE BOVINOS AO CARRAPATO RHIPICEPHALUS MICROPLUS}

gamma chain in tick-resistant and tick-susceptible breeds of cattle. Immunogenetics, 63: 319-324.

De la Fuente, J., Almazán, C., Canales, M., Lastra, J.M. de la, Kocan, K.M. and Willadsen, P. 2007. A ten-year review of commercial vaccine performance for control of tick infestations on cattle. Anim Health Res Rev, 8: 23-28.

Fraga, A.B., Alencar, M.M., Figueiredo, L.A., Razook, A.G. and Cyrillo, J.N.G. 2003. Análise de fatores genéticos e ambientais que afetam a infestação de fêmeas bovinas da raça Caracu por carrapatos (Boophilus microplus). Rev Bras Zootecn, 32: 1578-1586.

Frisch, J.E. and O'Neill, C.J. 1989. Comparative evaluation of beef cattle breeds of African, European and Indian origins. II. Resistance to cattle ticks and gastrointestinal nematodes. Anim Sci, 67: 39-48.

Frisch, J.E. 1994. Identification of a major gene for resistance to cattle ticks. World Congress on Genetic Applied to Livestock Production, 4. Proceedings ... Guelph, Ontario. pp. 293-295.

Gasparin, G., Miyata, M., Coutinho, L.L., Martinez, M.L., Teodoro, R.L., Furlong, J., Machado, M.A., Silva, M.V.G.B., Sonstegard, T.S. and Regitano, L.C.A. 2007. Mapping of quantitative trait loci controlling tick [Rhipicephalus (Boophilus) microplus] resistance on bovine chromosomes 5, 7 and 14. Anim Genet, 38: 453-459.

Gomes, A. 1992. Resistência a infestação natural por larvas, ninfas e adultos de Boophilus microplus em vacas zebuínas da raça Gir, em função de sua idade, da gestação, da lactação e da seleção para produção leiteira, com e sem tratamento carrapaticida, ao longo de 12 estações consecutivas de um triênio. Tese (Doutorado em Ciência). Universidade de São Paulo, São Paulo. 90 pp.

Henshall, J.M. 2004. A genetic analysis of parasite resistance traits in a tropically adapted line of Bos taurus. Aust J Agric Res, 55: 1109-1116. Kashino, S.S., Resende, J., Sacco, A.M., Rocha, C., Proenca, L., Carvalho, W.A., Firmino, A.A., Queiroz, R., Benavides, M., Gershwin, L.J. and Miranda Santos, I.K. de 2005. Boophilus microplus: the pattern of bovine immunoglobulin isotype responses to high and low tick infestations. Exp Parasitol, 110: 12-21.

Leemon, D.M., Turner, L.B. and Jonsson, N.N.
2008. Pen studies on the control of cattle tick Rhipicephalus (Boophilus) microplus with Metarhizium amisopliae (Sorokin). Vet Parasitol, 156: 248-260.

Li, R., Li, Y., Fang, X., Yang, H., Wang, J., Kristiansen, K. and Wang, J. 2009. SNP detection for massively parallel whole-genome resequencing. Genome Res, 19: 1124-1132.

Lôbo, R.B., Bittnecourt, T.C.B.S.C. and Pinto, L.F.B. 2010. Progresso científico em melhoramento animal no Brasil na primeira década do século XXI. Rev Bras Zootecn, 39: 223-235.

Machado, M.A., Azevedo, A.L.S., Teodoro, R.L., Pires, M.A., Peixoto, M.G.C.D., Freitas, C. de, Prata, M.C.A., Furlong, J., Silva, M.V.G.B da, Guimarães, S.E.F., Regitano, L.C.A., Coutinho, L.L., Gasparin, G. and Verneque, R.S. 2010. Genome wide scan for quantitative trait loci affecting tick resistance in cattle (Bos taurus $\mathrm{x}$ Bos indicus). BMC Genomics, 11: 1-11.

Martinez, M.L., Silva, M.V.G.B. da, Machado, M.A., Nascimento, C.S. do, Campos, A.L., Guimarães, M.F.M., Furlong, J., Pires, M.F.A. and Teodoro, R.L. 2004. Associação do gene candidato BoLADRB3.2 com resistência a ectoparasitas em bovinos. Reunião Anual da Sociedade Brasileira de Zootecnia, 41. Anais... Campo Grande, MS. Martinez, M.L., Machado, M.A., Nascimento, C.S., Silva, M.V.G.B., Teodoro, R.L., Furlong, J., Prata, M.C.A., Campos, A.L., Guimarães, M.F.M., Azevedo, A.L.S., Pires, M.F.A. and Verneque, R.S. 2006. Association of BoLA-DRB3.2 alleles with tick (Boophilus microplus) resistance in cattle. Genet Mol Res, 5: 514-524.

Martinez, R., Toro, R., Montoya, F., Burbano, M., Tobón, J., Gallego, J. and Ariza, F. 2005. Caracterización del lócus BoLA-DRB3 em ganado criollo colombiano y asociación com resistencia a enfermedades. Arch Zootec, 54: 349-356.

Mattioli, R.C., Pandey, V.S., Murray, M. and Fitzpatrick, J.L. 2000. Immunogenetic influences on tick resistance in African cattle with particular reference to trypanotolerant N'Dama (Bos taurus) and trypanosusceptible Gobra zebu (Bos indicus) cattle. Acta Trop, 75: 263-277.

Moraes, F.R., Moraes, J.R.E, Costa, A.J., Rocha, U.F. and Ardisson, F.A. 1992. A comparative study of lesions caused by different parasitic stages of Boophilus microplus (Canestrini) in the skins of naturally infested taurine and 
zebuine hosts. The correlation of tick resistance with mast cell counts in the host's skin. Braz. J Vet Res Anim Sci, 29: 378-383.

Oliveira, G.P., Alencar, M.M. and Freitas, A.R. 1989. Resistência de bovinos ao carrapato Boophilus microplus. II. Infestação Natural. Pesq Agropec Bras, 24: 1267-1271.

Piper, E.K., Jackson, L.A., Bagnall, N.H., Kongsuwan, K.K., Lew, A.E. and Jonsson, N.N. 2008. Gene expression in the skin of Bos taurus and Bos indicus cattle infested with the cattle tick, Rhipicephalus (Boophilus) microplus. Vet. Immunol Immunopathol, 126: 110-119.

Piper, E.K., Jonsson, N.N., Gondro, C., Lew-Tabor, A.E., Moolhuijzen, P., Vance, M.E. and Jackson, L.A. 2009. Immunological profiles of Bos taurus and Bos indicus cattle infested with the cattle tick, Rhipicephalus (Boophilus) microplus. Clin Vaccine Immunol, 16: 1074-1086.

Porto Neto, L.R., R.J. Bunch, B.E. Harrison and W. Barendse. 2011. DNA variation in the gene ELTD1 is associated with tick burden in cattle. Anim Genet, 42: 50-55.

Piper, E.K., Jackson, L.A., Bielefeldt-Ohmann, H., Gondro, C., Lew-Tabor, A.E. and Jonsson, N.N. 2010. Tick-susceptible Bos taurus cattle display an increased cellular response at the site of larval Rhipicephalus (Boophilus) microplus attachment, compared with tick-resistant Bos indicus cattle. Int J Parasitol, 40: 431-441.

Porto Neto, L.R., Bunch, R.J., Harrison, B.E., Prayaga, K.C. and Barendse, W. 2010a. Haplotypes that include the integrin alpha 11 gene are associated with tick burden in cattle. BMC Genet, 11: 55.

Porto Neto, L.R., Piper, E.K., Jonsson, N.N., Barendse, W. and Gondro, C. 2010b. Metaanalysis of genome wide association and gene expression studies to identify candidate genes for tick burden in cattle. World Congress of Genetics Applied to Livestock Production, 9. Leipzig. Germany. p. 664.

Regitano, L.C.A., Oliveira, M.C.S., Alencar, M.M., Carvalho, M.E., Andréo, R., Moreira, I.C., Néo, T.A., Barioni Jr., W. and Silva, A.M. 2006. Avaliação da resistência de bovinos de diferentes grupos genéticos ao carrapato e à babesiose. Boletim de Pesquisa e Desenvolvimento. Embrapa Pecuária Sudeste. São Carlos, SP. no 9.48 pp.
Regitano, L.C.A., Ibelli, A.M.G., Gasparin, G., Miyata, M., Azevedo, A.L.S., Coutinho, L.L., Teodoro, R.L., Machado, M.A., Silva, M.V.G.B., Nakata, L.C., Zaros, L.G., Sonstergard, T.S., Silva, A.M. and Alencar, M.M. 2008. On the search for markers of tick resistance in bovines. Dev Biologicals, 132: 225-230.

Rodríguez Valle, M., Méndez, L., Valdez, M., Redondo, M., Espinosa, C.M., Vargas, M., Cruz, R.L., Barrios, H.P., Seoane, G., Ramírez, E.S., Boué, O., Vigil, J.L., Machado, H., Nordelo, C.B. and Piñeiro, M.J. 2004. Integrated control of Boophilus microplus ticks in Cuba based on vaccination with the anti-tick vaccine Gavac. Exp Appl Acarol, 34: 375-382.

Samish, M., Ginsberg, H. and Glazer, I. 2008. Antitick biological control agents: assessment and future perspectives. In: Bowman, A.S. and P.A. Nutall. Ticks- Biology, Disease and Control. Cambridge University Press. New York. pp. 447-469.

Santi, L., Silva, W.O., Pinto, A.F.M., Schrank, A. and Vainstein, M.H. 2009. Differential immunoproteomics enables identification of Metarhizium anisopliae proteins related with Rhipicephalus microplus infection. Res Microbiol, 160: 824-828.

Santos Jr., J.C.B., Furlong, J. and Daemon, E. 2000. Controle do carrapato Boophilus microplus (Acari: Ixodidae) em sistemas de produção de leite da microrregião fisiográfica fluminense do grande Rio. Cienc Rural, 30: 305-311.

Silva, A.M., Alencar, M.M., Regitano, L.C.A., Oliveira, M.C.S. and Barioni Jr., W. 2006a. Natural infestations of beef cattle females by external parasites in southern Brazil. World Congress on Genetics Applied to Livestock Production, 8. Belo Horizonte, MG.

Silva, A.M., Alencar, M.M., Regitano, L.C.A. and Oliveira, M.C.S. 2006b. Estimativas de herdabilidade e repetibilidade do grau de infestação por ectoparasitos em fêmeas de quatro grupos genéticos de bovinos de corte. Reunião Anual da Sociedade Brasileira de Zootecnia, 43. João Pessoa, PB.

Silva, A.M., Alencar, M.M., Regitano, L.C.A., Oliveira, M.C.S. and Barioni Jr., W. 2007. Artificial infestation of Boophilus microplus in beef cattle heifers of four genetic groups. Genet Mol 


\section{RESISTÊNCIA DE BOVINOS AO CARRAPATO RHIPICEPHALUS MICROPLUS}

Biol, 30: 1150-1155.

Silva, A.M., Alencar, M.M., Regitano, L.C.A. and Oliveira, M.C.S. 2010. Infestação natural de fêmeas bovinas de corte por ectoparasitas na Região Sudeste do Brasil. Rev Bras Zootecn, 39: 1477-1482.

Skallová, A., Lezzi, G., Ampenberger, F., Kopf, M. and Kopecky, J. 2008. Tick saliva inhibits dendritic cell migration, maturation and function while promoting development of Th2 responses. J Immunol, 180: 6186-6192.

Sonenshine, D.E., Kocan, K.M. and Fuente, J. de la 2006. Tick control: further thoughts on a research agenda. Trends Parasitol, 22: 550551.

Soulsby, E.J.L. 1987. The evasion of the immune response and immunological unresponsiveness: parasitic helminthes infection. Immunol Lett, 16: 315-320.

Szabó, M.P.J., Aoki, V.L., Sanches, F.P.S., Aquino, L.P.T.C.T., Garcia, M.V., Machado, R.Z. and Bechara, G.H. 2003. Antibody and blood leukocyte response in Rhipicephalus sanguineus (Latreille, 1806) tick infested dogs and guinea pigs. Vet Parasitol, 115: 49-59.

Takeshima, S. and Aida, Y. 2006. Structure, function and disease susceptibility of the bovine major histocompatibility complex. Anim Sci J, 77: 138-150.

Tizard, I.R. 2008. Imunologia Veterinária: Uma Introdução. 8ed. Elsevier. Rio de Janeiro. 587p.

Turner, L.B., Harrison, B.E., Bunch, R.J., Porto Neto, L.R., Li, Y.T. and Barendse, W. 2010. A genome wide association study of tick burden and milk composition in cattle. Anim Prod Sci, 50: 235-245.

Turni, C., Lee, R.P. and Jackson, L.A. 2002. Effect of salivary gland extracts from the tick, Boophilus microplus, on leucocytes from Brahman and
Hereford cattle. Par Immunol, 24: 355-361.

Untalan, P.M., Pruett, J.H. and Steelman, C.D. 2007. Association of the bovine leukocyte antigen major histocompatibility complex class II DRB3*4401 allele with host resistance to the Lone Star tick, Amblyomma americanum. Vet Parasitol, 145: 190-195.

Utech, K.B.W. and Wharton, R.H. 1982. Breeding for resistance to Boophilus microplus in Australian Illawara Shorthorn and Brahman $x$ Australian Illawara Shorthorn cattle. Aust Vet J, 58: 41-46.

Utech, K.B.W., Wharton, R.H. and Kerr, D.J. 1978a. Resistance to $B$. microplus (Canestrini) in different breeds of cattle. Aust J Agric Res, 29: 885-895.

Utech, K.B.W., Seifert, G.W. and Wharton, R.H. 1978b. Breeding Australian Illawarra Shorthorn cattle for resistance to Boophilus microplus. I. Factors affecting resistance. Aust J Agric Res, 29: 411-422.

Veríssimo, C.J., Nicolau, C.V.J., Cardoso, V.L. and Pinheiro, M.G. 2002. Haircoat characteristics and tick infestation on Gyr (Zebu) and crossbreed (Holstein x Gyr) cattle. Arch Zootec, 51: 389-392.

Wagland, B.M. 1975. Host resistance to cattle tick (Boophilus microplus) in Brahman (Bos indicus) cattle. I. Response of previously unexposed cattle to four infestations with 20.000 larvae. Aust J Agric Res, 26: 1073-1078.

Willadsen, P. 2006. Tick control: thoughts on a research agenda. Vet Parasitol, 138: 161-168.

Willadsen, P. 2008. Anti-ticks vaccines. In:Bowman, A.S. and P.A. Nutall. Ticks-Biology, Disease and Control. Cambridge University Press. New York. pp. 447-469.

Womack, J.E. 1993. The goals and status of the bovine gene map. J Dairy Sci, 76: 219-226. 